\title{
Factors That Influence Students To Participate In Team Decision Making
}

William R. Forrester, Ph.D., Kennesaw State University, USA

Armen Tashchian, Ph.D., Kennesaw State University, USA, and American University of Armenia, Armenia

\begin{abstract}
This study investigated the effects of personality on participation in decision making in a sample of 225 business students. The Neo-FFI scale was used to measure the five personality dimensions of openness, agreeableness, extroversion, conscientiousness and neuroticism. Analysis indicated that personality dimensions, extroversion and conscientiousness, influenced participation. No participation influence was observed for other personality variables. Partial Least Squares modeling indicated that the extroversion and conscientiousness influences were mediated by other variables. The effect of extroversion was fully mediated by an intervening variable representing the choice to use competitive strategies for achieving success. The effect of conscientiousness was mediated by citizenship behavior as well as the choice to use competitive strategies.
\end{abstract}

Keywords: Team Participation; Personality; Success Motivation; Partial Least Squares

\section{INTRODUCTION}

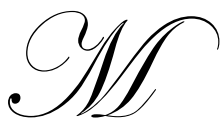

any of the activities involved in business education occur in the context of student teams. Business education courses use teams for case analyses, field study projects, simulations, discussions, and in-class presentation of reports. These activities are important determinants of learning outcomes and depend upon the active engagement of team members (Uslay 2007). In addition, participation affects numerous individual outcomes including the ways in which students are perceived by peers, their grades, and their levels of learning satisfaction (Vik 2001). Yet educators and students consistently report that participation is difficult to achieve, and frequently cite lack of participation as a source of dissatisfaction within student teams (Napier and Johnson 2007).

Educators suggest that there are both situational and structural reasons why team participation is difficult to achieve. Expectations for participation may not be clear, students may not receive instruction in how to participate in teams, and the communication mechanisms necessary to support participation may not be adequate (Snyder 2009, Carnaghan and Webb 2007, Ji-Tsung and Marakas 2006). They may lack motivation to engage in group processes, or they may lack confidence in their ability to participate successfully.

There is a need for a better understanding of what encourages students to participate in teams. A more complete knowledge of team participation offers the potential for a range of benefits in improving team formation, team structure, stress reduction, and improved team performance.

\section{LITERATURE}

Scholars have conceptualized participation in decision making (PDM) in different ways. A meta-analysis by Cotton, et. al. (1988) identified a range of participation forms differing in focus and duration. These included participation in work decisions, consultative participation, short-term participation, informed participation, employee ownership, and representative participation. While effects differed among the different forms, participation in work decisions consistently showed effects on performance outcomes and satisfaction. Participation in work decisions focus on decisions about the work itself, what work is to be done, who is responsible for doing the work, and how it is to be organized and carried out. 
Miller and Monge (1986) proposed three models to explain the effects of participation on productivity and job satisfaction. The cognitive model views the effects as the result of job knowledge. Under this model the effects of participation are greater on productivity than satisfaction. The affective model predicts that participation will lead to heightened job satisfaction with subsequent increases in productivity. Under this model, participation has a greater effect on satisfaction than upon productivity. The contingency model predicts different outcomes of participation depending upon the situation.

\section{Effects of Participation}

Participation in decision making produces numerous beneficial outcomes. These include increased feelings of self efficacy and reduced levels of stress, increased organizational commitment and engagement in organizational citizenship behaviors, and improved job performance and increased job satisfaction.

Latham and his colleagues found that participation in strategy formulation significantly enhanced performance in ways that were due not only to the strategies themselves, but also to increased feelings of selfefficacy that resulted from the participation in goal setting and the formulation of strategies (Latham, Winters, and Locke 1994). They suggested that formulating successful strategies builds task confidence because team members expect the strategies to be effective. They noted that this self-confidence increases efficacy in implementation of the strategies since self confident team members are more able to perform tasks with greater focus and less distraction resulting from self-doubt.

Participation in decision making is also associated with stress reduction. In an experiment conducted in a hospital outpatient facility using nurses and hospital clerical staff as subjects, Jackson found that subjects receiving the "high participation' treatment, reported lower levels of role conflict, role ambiguity, and emotional stress than was reported by subjects in the "low participation" treatment group. These effects of participation were subsequently associated with lower levels of job absence and lower levels of job turnover. Jackson concluded that participation was an important determinant of numerous beneficial outcomes both at the individual and organizational levels (Jackson, 1983).

The effects of participation are underscored more strongly in studies that consider the effects of nonparticipation; particularly non-participation resulting from ostracism. There is evidence that exclusion from the decision making process leads to a range of negative psychological consequences. These include social anxiety, losses of self-esteem, sadness, and anger (Jones et. al. 2009, Oaten et. al. 2008).

In a meta-analysis, Pereira and Osburn (2007) noted the consistent positive effects of increased participation on productivity, job satisfaction, and organizational commitment. Research shows that other variables moderate these effects. VanYperen (1998) showed that information-support strongly influenced the beliefs of nurses that they were equitably treated by the hospitals for which they worked. These effects were highest among nurses with low self-efficacy perceptions.

Witt, Andrews, and Kacmar (2000) found that public sector employees who engaged in consensus decision making with their supervisors were less sensitive to the effects of organizational politics. Those who participated in decision making had higher levels of job satisfaction than those who did not, and their satisfaction was less impacted by organizational politics.

\section{Causes of Participation}

While the majority of studies have focused on the outcomes of PDM, fewer have focused on identifying and evaluating the factors that encourage participation. Nevertheless there is evidence that participation is influenced by three factors that appear to be relevant in the context of student teams; conscientiousness, loyalty, and choice of success strategies.

Conscientiousness is one of five personality dimensions relevant in explaining a wide array of behaviors in organizational contexts. It reflects behaviors directly related to team participation including adherence to group 
rules regarding attendance, punctuality, and respect for team processes (Costa and McCrae 1992). In a larger scale study of team behaviors in a hospital setting, Konovsky and Organ (1996) found that conscientiousness was highly correlated with beneficial team behaviors including attendance at meetings, keeping other workers informed about developments within the organization, reading and answering mail, and otherwise practicing constructive and appropriate forms of involvement in the governance of the workplace.

These finding are consistent with research in other contexts. Bolin and Neuman (2006) evaluated the effects of personality variables that influence willingness to engage in group processes. They noted numerous links between conscientiousness and avoidance of social loafing and active participation in group processes. Tan and Tan (2008) found strong support for the role of conscientiousness in determining participating. Their findings suggest that the levels of responsibility that individuals feel toward their work and work groups influenced their likelihood of engaging in behaviors that enhanced group performance. Loyalty to the group also influences decisions to participate. Van der Gegt, Van de Vleirt, and Oosterhof (2003) showed that team identification was a significant predictor of the extent to which employees go above and beyond the call of duty in contributing to the functioning of their work teams.

Andersson (2009) found that participation in searches for solutions to social problems depended on motivational factors including beliefs that participation would lead to workable solutions, and the presence of incentives. Pearson (1991) found that decisions to continue participation in self-monitored group tasks was influenced by participants' motivation for group achievement and the availability and quality of feedback about the effectiveness of efforts to achieve desired outcomes. These findings are consistent with those of Latham et.al. who found that cognitions about the benefits of participation were mediated by motivational factors in determining participation outcomes (Latham, Winters, and Locke 1994). Of particular relevance is the choice of strategies for bringing about success. Simmons et. al. (1988) showed distinct differences in preferences for using cooperative strategies in contrast to competitive strategies for bringing about success.

\section{PURPOSE OF THE RESEARCH}

Research suggests that participation in decision making is influenced by three factors that are relevant in the context of student teams; conscientiousness, loyalty, and success motivation. However, many of the past studies have been experimental, and few have been conducted in academic team contexts. As a result, the applicability of findings to student teams is questionable. The purpose of this study is to investigate individual level factors influencing participation in the context of higher education student teams. Based on the previous literature review we offer the following hypotheses:

H1: Personality (five NEO-FFI personality dimensions of agreeableness, conscientiousness, extroversion, neuroticism and openness) will be related to level of participation in team decision making

H2: Personality will be related to participation in team decision making mediated by the level of organizational citizenship (helping and loyal) behaviors

H3: Personality will be related to participation in team decision making mediated by preferences for competitive and cooperative strategies for success

\section{METHOD}

Subjects for the study were 225 business students (54 percent male) enrolled in business courses at a southeastern university. The students were working adults, ranging in age from 20 to 52 with a mean age of 26.7 years. Sixty percent of students reported working full-time and 28 percent were working part-time. Only 11 percent of students were not employed at the time of the survey. The average for full time and part-time work experience was 5.9 and 4.8 years respectively. Data was collected over a four-semester span in nine sections of four different marketing courses. Students comprised 45 teams ranging in size from three to seven members with four being the modal team size. Team memberships were voluntary; however, in some instances the instructor reassigned students to teams that contained fewer members. Students participated in the study for course credit. 
For each course, data was collected in three phases. During the first phase the students were organized into teams and provided baseline information on personality and their attitudes toward group work and team membership. In the second phase, they provided data on their organizational citizenship behaviors; levels of participation in decision making and use of cooperative and competitive strategies for success. In the final phase, they provided demographic and work related data for classification purposes.

Personality was measured using the Neo Five-Factor Inventory (NEO-FFI). This inventory profiles each student's emotional, interpersonal, experiential, attitudinal, and motivational styles (Costa and McCrae 1992). It consists of sixty items anchored by "strongly disagree' to 'strongly agree' and measures personality on the dimensions of agreeableness, conscientiousness, extraversion, neuroticism and openness

Phase two data collection took place approximately six weeks later, after teams had sufficient time to work together on a variety of tasks. Students provided information about their organizational citizenship behaviors (Van der Vegt, Van de Vliert and Oosterhof (2003), success strategies (Simmons, Wehner, Tucker and King 1988) and level of participation in decision making (VanYperen, Van den Berg and Willering 1999).

Organizational citizenship behavior (OCB) was measured using an 8-item scale. The items measure helping and loyalty behaviors among individuals. This form of organizational citizenship scale is useful because it uses self-reports instead of ratings by peers or supervisors. The helping behavior subscale had a Cronbach's alpha of 0.791 . The loyal behavior subscale had an alpha of 0.774 .

Level of participation in group decision making (Van Veldhoven and Meijman 1944) is an 8-item scale developed to explore the link between participation in decision-making and organization citizenship behavior. The items are scored as a four point verbal frequency scale anchored by 'never' to 'always'. For the present sample the scale had a Cronbach's alpha of 0.824 .

Finally, students completed a 17 item inventory measuring their motivation to use cooperative or competitive strategies for achieving success (Simmons, Wehner, Tucker and King 1988). The two dimensions of the scale are: use of competitive strategies and use of cooperative strategies. Respondents reported frequency of their various success strategies by checking the five point scale anchored by never to always. Cronbach's alphas were 0.753 and 0.736 for competitive and cooperative strategies scales respectively. Scale mean, item mean and Cronbach's alpha for measures used in the study are listed in Table 1.

Table 1. Scale Properties for Measures Used in the Study

\begin{tabular}{lcccc}
\hline & $\begin{array}{c}\text { Number } \\
\text { of Items }\end{array}$ & $\begin{array}{c}\text { Scale } \\
\text { Mean }\end{array}$ & $\begin{array}{c}\text { Item } \\
\text { Mean }\end{array}$ & $\begin{array}{c}\text { Cronbach's } \\
\text { Alpha }\end{array}$ \\
\hline Personality Measures & & & & \\
Agreeableness (AGR) & 12 & 43.85 & 3.65 & 0.721 \\
Conscientiousness (CON) & 12 & 46.45 & 3.87 & 0.832 \\
Extroversion (EXT) & 12 & 44.51 & 3.71 & 0.802 \\
Neuroticism (NEU) & 12 & 29.42 & 2.45 & 0.862 \\
Openness (OPN) & 12 & 40.11 & 3.34 & 0.677 \\
& & & & \\
Organizational Citizenship Behaviors & & & & \\
Helping Behavior (OCB-HLP) & 4 & 16.84 & 4.21 & 0.791 \\
Loyal Behavior (OCB-LB) & 4 & 15.74 & 3.94 & 0.774 \\
& & & & \\
Success Motivation & 7 & 26.33 & 3.76 & 0.736 \\
Cooperative Success Strategies (COOP) & 10 & 39.26 & 3.93 & 0.753 \\
Competitive Success Strategies (COMP) & & & & \\
Participation in Decision Making & 8 & 23.87 & 2.94 & 0.824 \\
\hline
\end{tabular}


The last phase of data collection was conducted at the end of the semester. At that time, students provided demographic data and indicated their perceptions of team effort, effectiveness, and task satisfaction.

\section{ANALYSIS AND RESULTS}

Hypotheses were tested by using partial least squares structural equation modeling (PLS-SEM). PLS-SEM is similar to multiple regression analysis with the objective of maximizing the explained variance of endogenous latent constructs (dependent variables). Recent methodological advancements along with the availability of statistical software, have contributed to the usefulness and popularity of PLS-SEM (Hair, Ringle, and Sarstedt 2011).

Since the focus of this study is to predict relationships between personality variables, organizational citizenship, success motivators and participation in decision making, PLS-SEM was chosen as the appropriate method for analysis. It is well suited for exploratory research with the aim of theory development.

Figure 1 displays the Participation in Decision Making (PDM) model where the five personality dimensions are hypothesized to have a direct effect on PDM (Hypothesis 1). Figure 2 presents the indirect effects of the five personality variables on PDM through organizational citizenship (OCB) and cooperative and competitive success strategies (CCSC) (Hypotheses 2 and 3).

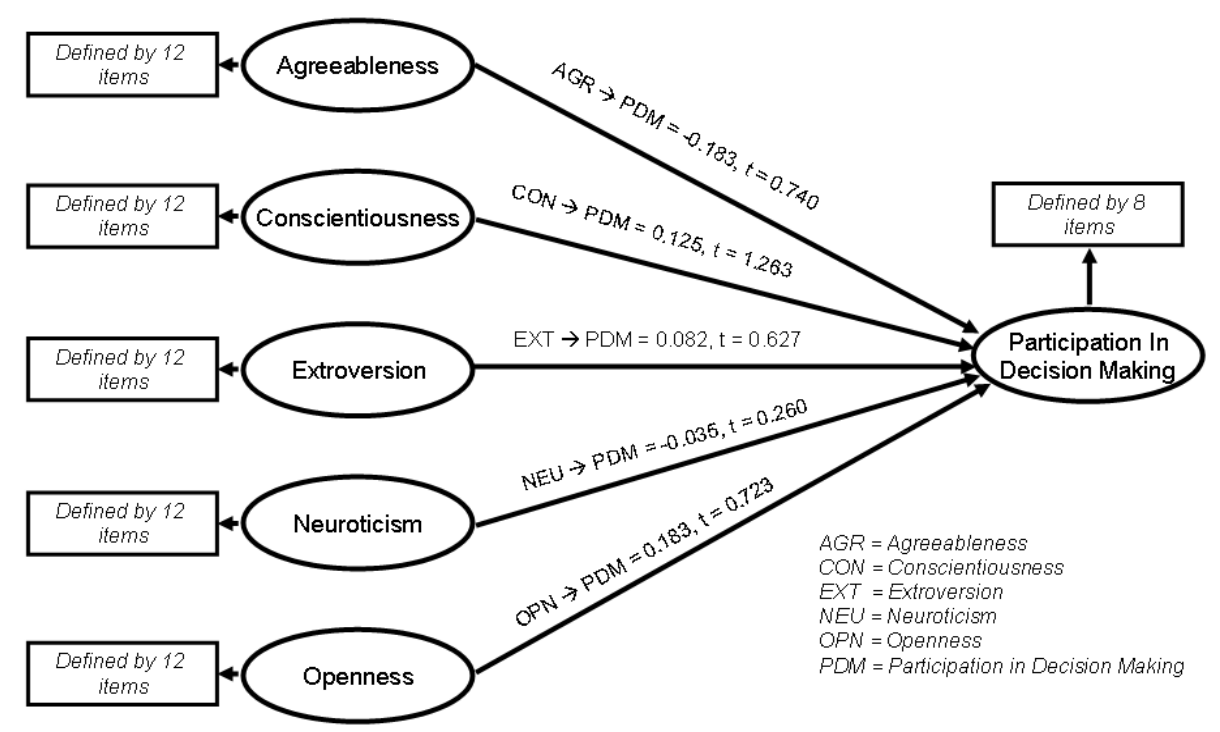

Figure 1. Direct Impact of Personality on Student Participation in Team Decision Making

In examining the impact of personality variables on PDM it appears that none of the five personality dimensions had a direct significant impact on respondents' participation in decision making. T-values of all path coefficients were less than 1.96. As such, Hypothesis 1 was not supported. 


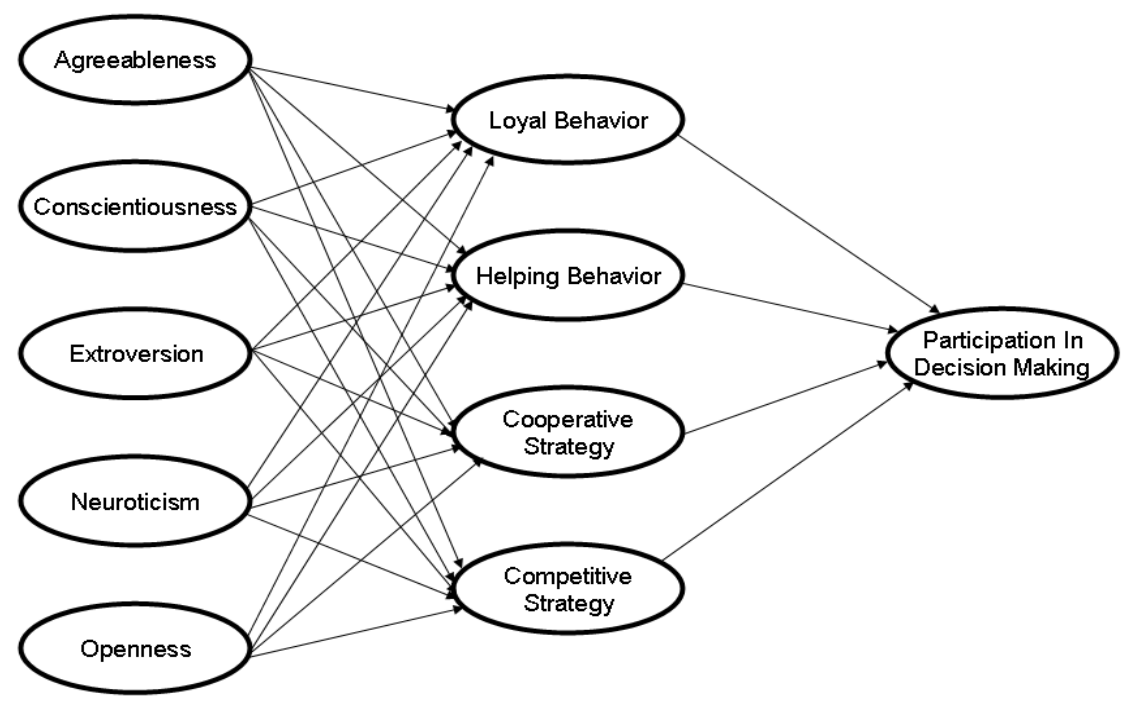

Figure 2. Factors Influencing Student Participation in Team Decision Making

Next we examined the relationship among the five personality variables and Organizational Citizenship Behavior (Table 2). Of the ten paths connecting personality to Helping and Loyal Behaviors, only Conscientiousness was significantly related to OCB $(\mathrm{CON} \rightarrow \mathrm{OCB}-\mathrm{LB}=0.272, \mathrm{t}=2.21)$. Individuals with high levels of conscientiousness are more likely to put extra time to finish team work tasks; do things that are not required but contribute to the success of the team, and never avoid extra duties and responsibilities.

Table 2. The Impact of Personality on Organizational Citizenship Behaviors

\begin{tabular}{lcccc}
\hline & \multicolumn{2}{c}{$\begin{array}{c}\text { Organizational Citizenship Behavior (OCB) } \\
\text { Loyal Behavior } \\
\text { Neo-FFI }\end{array}$} & $\begin{array}{c}\text { Coefficient } \\
\text { Coefficient }\end{array}$ & t-value \\
\hline Agreeableness & 0.181 & 1.484 & 0.140 & 1.070 \\
Conscientiousness & 0.132 & 0.939 & 0.272 & $2.203 *$ \\
Extroversion & 0.070 & 0.644 & -0.123 & 1.083 \\
Neuroticism & 0.042 & 0.264 & 0.026 & 0.155 \\
Openness & 0.090 & 0.549 & -0.001 & 0.003 \\
\hline
\end{tabular}

$* p<0.05$

Finally, we tested the significance of path coefficients connecting personality to preferences for competitive and cooperative success strategies. Results in Table 3 show that only three personality variables are related to competitive and cooperative strategies for success.

Agreeableness was significantly related to cooperative strategy $(\mathrm{AGR} \rightarrow \mathrm{COOP}=0.311, \mathrm{t}=2.21)$. This indicates that agreeable students believe that success can be achieved while working with others and that joint effort is the best way to achieve success. They also feel that shared efforts can lead to both individual and team success.

On the other hand, Conscientiousness was significantly related to preference for competition as a success strategy $(\mathrm{CON} \rightarrow \mathrm{COMP}=0.356, \mathrm{t}=2.44)$. Conscientious students feel it is important for them to do better than others; believe that successful people have satisfying lives and they enjoy the challenge of competing against others. These students are happier when they strive to succeed 
Extroversion had a positive and significant impact on both the cooperative and competitive strategies for success $(\mathrm{EXT} \rightarrow \mathrm{COMP}=0.279, \mathrm{t}=2.69, \mathrm{EXT} \rightarrow \mathrm{COOP}=0.321, \mathrm{t}=2.73)$. This shows that extroverted students like to have a lot of people around; enjoy talking with a variety of individuals; are full of energy and like to work in groups rather than working individually. As such, extroverted students appear to use both cooperative and competitive strategies to achieve success.

Table 3. The Impact of Personality on Success Motivation

\begin{tabular}{|c|c|c|c|c|}
\hline \multirow[b]{3}{*}{ Neo-FFI } & \multicolumn{4}{|c|}{ Strategy for Success } \\
\hline & \multicolumn{2}{|c|}{ Competitive Strategy } & \multicolumn{2}{|c|}{ Cooperative Strategy } \\
\hline & Coefficient & t-value & Coefficient & t-value \\
\hline Agreeableness & -0.074 & 0.516 & 0.311 & $2.201 *$ \\
\hline Conscientiousness & 0.356 & $2.443^{*}$ & 0.002 & 0.014 \\
\hline Extroversion & 0.279 & $2.694 *$ & 0.321 & $2.723 *$ \\
\hline Neuroticism & 0.152 & 1.187 & 0.016 & 0.118 \\
\hline Openness & -0.193 & 0.770 & -0.048 & 0.261 \\
\hline
\end{tabular}

$* p<0.05$

After establishing the relationships between personality variables and the two mediator constructs, the next two hypotheses are concerned with the role of Organizational Citizenship Behaviors and CCSC on participation in decision making (PDM). Table 4 presents the path coefficients of the two constructs on the participation in decision making. As can be seen, loyalty behavior was significantly related to participation in decision making (OCB$\mathrm{LB} \rightarrow \mathrm{PDM}=0.309, \mathrm{t}=2.30$ ). Students who are willing to shoulder more of the team work and not avoid extra responsibilities have a significant say and influence in decision making in their teams. Furthermore, they have an influence on the division of work among team members and are more likely to discuss these issues with the professor.

Finally, individuals who use competitive strategies for success are more likely to actively participate in team decision making $(\mathrm{COMP} \rightarrow \mathrm{PDM}=0.299, \mathrm{t}=2.95)$. In order to succeed these individuals take the initiative in team work, task allocation and interaction with the instructor. These findings provide partial support for hypothesis 2 and 3.

Based on these findings, the model presented in Figure 2 was revised by removing the non-significant paths. The revised model is presented in Figure 3. This shows no direct relationships between any of the five personality constructs and PDM. Only Conscientiousness and Extraversion were related to the mediated constructs of Loyalty and Competitive Success Strategy. Agreeableness was not presented in the revised model even though it had a direct relationship with helping behavior. This reflects the fact that helping behavior did not relate to PDM and as a result, there is no relationship between agreeableness and PDM.

Table 4. Impact of Citizenship Behavior and Success Motivation on Participation in Decision Making

\begin{tabular}{|c|c|c|}
\hline \multicolumn{3}{|c|}{ Participation in Decision Making } \\
\hline & Coefficient & t-value \\
\hline \multicolumn{3}{|l|}{ Organizational Citizenship Behavior } \\
\hline Helping Behavior & 0.139 & 1.120 \\
\hline Loyal Behavior & 0.309 & $2.300 *$ \\
\hline \multicolumn{3}{|l|}{ Success Motivation } \\
\hline Competitive Strategy for Succsss & 0.299 & $2.959 *$ \\
\hline Cooperative Strategy for Success & -0.034 & 0.226 \\
\hline
\end{tabular}




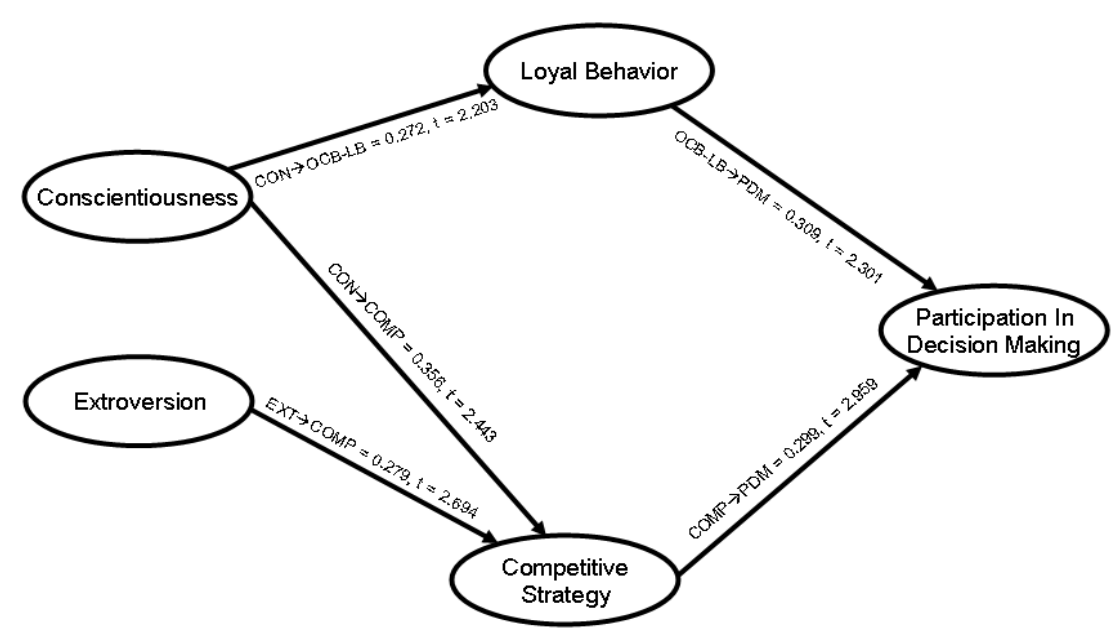

Figure 3. Revised Model of Factors Influencing Student Participation in Team Decision Making

In conclusion, there is evidence that extroversion and conscientiousness impact participation in decision making. This impact is mediated by loyal behavior and competitive strategy for success. Furthermore, neither helping behavior nor the use of cooperate success strategies affect levels of participation in team work.

\section{DISCUSSION}

Results of the study provide new insights into the relationship between personality and participation in team decision making. Two personality variables, conscientiousness and extroversion, were identified as significantly related to participation. Results show that the effects of these personality dimensions are mediated by engagement in loyalty behaviors, and by the belief that competitive behaviors increase the likelihood of achieving success.

These findings suggest a number of practical consequences in terms of encouraging and enhancing participation in student team settings. They suggest that participation can be facilitated through team structure by ensuring that teams have members who are conscientious and extroverted. This suggests that personality dimensions should be considered at the time teams are formed, and that efforts be made to ensure that conscientiousness and extroversion are represented in the personalities of team members. It is not known if there are threshold levels of conscientiousness or extroversion that must be met as a pre-condition to desired participation. This is a question for future research.

Results also underscore the importance of organizational citizenship behaviors. Students who participated most actively were those high in conscientiousness who exhibited a range of loyalty behaviors reflecting willingness to take on team responsibilities beyond the levels normally expected or required. Past studies have shown that such behaviors are associated with team leadership and that other team members defer to those exhibiting such behaviors (Watson and Hoffman 2004)). These studies have shown that deferring members treat those exhibiting loyalty behaviors as having 'earned' the right to make team decisions (Watson and Hoffman 2004, Wickham and Walther 2007). This suggests that while loyalty behaviors should be encouraged, all members of student teams should be aware that they are not pre-conditions for involvement. All team members should be explicitly welcomed to participate regardless of the intensity of their loyalty behaviors. 
Both conscientiousness and extroversion were related to success motivation and the belief that competitive behaviors increase the likelihood of successful outcomes. Extroverted and conscientious students are more active participants in team decision making. Before practical consequences can be formulated, however, additional questions need to be answered. This participation may take the form of competing with other team members to ensure the adoption of their own ideas for achieving team success. However, competition can be also viewed from an inter-team perspective. It may be that the participation results from the belief that sharing ideas and finding the right competitive strategy increases the likelihood of winning in situations such as simulations in which teams are in competition with other teams for grades and recognition rewards. Further research is needed to further clarify the nature of competitiveness perceptions and the degree to which motivation is affected by different types of rewards.

\section{AUTHOR INFORMATION}

William Forrester received his Ph.D. in Marketing in 1986 from the University of Tennessee. He currently works as Professor of Marketing in the Coles College of Business at Kennesaw State University. He has published in the Journal of the Academy of Marketing Science, the Journal of Economic Psychology, and the Journal of Applied Business Research, and numerous other outlets. Email: wforrest@kennesaw.edu

Armen Tashchian is Professor of Marketing in the Coles College of Business at Kennesaw State University and Visiting Professor of Marketing at the American University of Armenia. He received his Ph.D. in Marketing from the University of Texas in 1980. He has published in numerous academic journals including the Journal of Marketing, the Journal of Marketing Research, and the Journal of the Academy of Marketing Science. Email: atashchi@kennesaw.edu.

\section{REFERENCES}

1. Andersson, K. (2009). Motivational dilemmas in collaborative learning activities: The case of the Swedish International Development Cooperation Agency (SIDA). Public Administration \& Development, 29 (5), 341-351.

2. Bolin, A. \& Neuman, G. (2006). Personality, process, and performance in interactive brainstorming groups. Journal of Business \& Psychology, 20 (4), 565-585.

3. Carnaghan, C. \& Webb, A. (2007). Investigating the effects of group response systems on student satisfaction, learning, and engagement in accounting education. Issues in Accounting Education, 22 (3), 391-409.

4. Costa, P. \& McCrae, R. (1992). Neo PI-R and Neo-FFI professional manual. Odessa, FL: Psychological Assessment Resources, Inc.

5. Cotton, J., Vollrath, D., Froggatt, K., Lengnick-Hall, M., \& Jennings, K. (1988). Employee participation: Diverse forms and different outcomes. Academy of Management Review, 13 (1), 8-22.

6. $\quad$ Hair, J., Ringle, C., \& Sarstedt, M. (2011). PLS-SEM: Indeed a silver bullet.” Journal of Marketing Theory and Practice, 19 (2), 139-151.

7. Jackson, S. (1983). Participation in decision making as a strategy for reducing job-related strain. Journal of Applied Psychology, 68 (1), 3-19.

8. Ji-Tsung, B., \& Marakas, G. (2006). The impact of operational user participation on perceived system implementation success: An empirical investigation. Journal of Computer Information Systems, 46 (5), 127-140.

9. Jones, E., Cater-Sowell, A., Kelly, J., \& Williams, K. (2009). I'm out of the loop': Ostracism through information exclusion. Group Processes \& Intergroup Relations, 12 (2), 157-174.

10. Konovsky, M., \& Organ, D. (1996). Dispositional and contextual determinants of organizational citizenship behavior," Journal of Organizational Behavior, 17 (3), 253-266.

11. Latham, G., Winters, D., \& Locke, E. (1994). Cognitive and motivational effects of participation: a mediator study. Journal of Organizational Behavior, 15 (1), 49-63.

12. Miller, K., \& Monge, P. (1986). Participation, satisfaction, and productivity: A meta-analytic review. Academy of Management Journal, 29 (4), 727-753.

13. Napier, N., \& Johnson, R. (2007). Technical projects: Understanding teamwork satisfaction in an introductory IS course. Journal of Information Systems Education, 18 (1), 39-48. 
14. Oaten, M., Williams, K., Jones, A. \& Zadro, L. (2008). The effects of ostracism on self-regulation in the socially anxious. Journal of Social and Clinical Psychology, 27 (5), 471-504.

15. Pearson, C. (1991). An assessment of extrinsic feedback on participation, role perceptions, motivation, and job satisfaction in a self-managed system for monitoring group achievement." Human Relations, 44 5), 517-537.

16. Pereira, G., \& Osburn, G. (2007). Effects of participation in decision making on performance and employee attitudes: A quality circles meta-analysis. Journal of Business \& Psychology, 22 (2), 145-153.

17. Simmons, C., Wehner, E., Tucker, S., \& King, C. (1988). The cooperative/competitive strategy scale: A measure of motivation to use cooperative or competitive strategies for success. The Journal of Social Psychology, 128 (2),199-205.

18. Snyder, L. (2009). Teaching teams about teamwork: Preparation, practice, and performance review. Business Communication Quarterly, 72 (1), 74-79.

19. Tan, H., \& Tan, M. (2008). Organizational citizenship behavior and social loafing: The role of personality, motives, and contextual factors. Journal of Psychology, 142 (1), 89-108.

20. Uslay, C. (2007). Case analyses with extensive student involvement: Management versus consultants case method (MCM). Marketing Education Review 17 (1), 21-27.

21. Van der Vegt, G., Van de Vliert, E., \& Oosterhof, A. (2003). Informational dissimilarity and organizational citizenship behavior: The role of Intra-team interdependence and team identification. Academy of Management Journal 46 (6), 715-727.

22. VanYperen, N. (1998). Informational support, equity and burnout: The moderating effect of self-efficacy. Journal of Occupational \& Organizational Psychology, 71 (1), 29-33.

23. VanYperen, N., Van de Berg, A., \& Willering, M. (1999). Towards a better understanding of the link between participation in decision-making and organizational citizenship behaviour: A multilevel analysis. Journal of Occupational \& Organizational Psychology, 72 (3), 377-392.

24. Vik, G. (2001). Doing more to teach teamwork than telling students to sink or swim. Business Communication Quarterly, 64 (4), 112-119.

25. Watson, C., \& Hoffman, R. (2004). The role of task-related behavior in the emergence of leaders: the dilemma of the informed woman. Group \& Organization Management, 29 (6), 659-685.

26. Wickham, K. \& Walther, J. (2007). Perceived behaviors of emergent and assigned leaders in virtual teams. International Journal of E-Collaboration, 3 (1), 1-17.

27. Witt, L., Andrews, M/, \& Kacmar, K. (2000). The role of participation in decision-making in the organizational politics-job satisfaction relationship. Human Relations, 53 (3), 341-358.

28. Wolfe, J, \& Luethge, D. (2003). The impact of involvement on performance in business simulations: An examination of Goosen's 'know little' decision-making thesis, Journal of Education for Business, 79 (2), 69-74. 